\title{
EFFECT OF INTEGRATED PEST MANAGEMENT TECHNOLOGY ON THE LIVELIHOODS OF SMALL-SCALE MAIZE PRODUCERS
}

\author{
Robert Ouko GWADA ${ }^{* 1}$ (iD), Hillary Kiplangat BETT ${ }^{1}$ (i), Kenneth Waluse SIBIKO ${ }^{2}$ (iD
}

\author{
Address: \\ ${ }^{1}$ Egerton University, Faculty of Agriculture, Department of Agricultural Economics and Agribusiness Management, \\ P.O Box 536-20115, Egerton Njoro, Kenya. \\ ${ }^{2}$ Maseno University, Faculty of Agriculture, Department of Agricultural Economics and Rural Development, P.O Box, \\ Private Bag, Maseno, Kenya. \\ * Corresponding author: oukogwada@gmail.com
}

\begin{abstract}
Research background: In Kenya, maize production has been severely constrained by parasitic pests and weeds such as Striga, stem borer, and fall armyworm. The government of Kenya and its partners have developed, disseminated, and promoted the continual uptake of integrated pest management technologies such as Push-Pull technology (PPT) as a way of addressing these constraints. Understanding the effect of these technologies on smallholder livelihoods is crucial, however, it is largely ignored in the literature.

Purpose of the article: This study evaluates the effect of continual uptake of PPT as an integrated pest management technology on livelihood outcomes of small-scale maize producers in Homa Bay County.

Methods: A multi-stage sampling procedure was used to select a sample of 240 respondents. Cross-sectional data were gathered through face-to-face interviews using a pretested semi-structured questionnaire, and analysed using descriptive statistics and propensity score matching models.

Findings \& Value added: Findings were that age, education level, total land owned, perception on Striga weed, stem borer, and fall armyworm severity, and land tenure positively influenced continual uptake of PPT, whereas the distance to nearest administrative centre was negatively associated with it. Propensity score matching results revealed that continual uptake of PPT had a positive and significant effect on household consumption expenditure and household dietary diversity, with a negative impact on poverty. The study, therefore, recommended policies that will ensure efficiency, literacy development, extension training, and resource availability among PPT non-adopters and dis-adopters to the level of the PPT continuous users.
\end{abstract}

Key words: integrated pest management; push-pull technology; continual uptake; livelihood outcomes; propensity score matching

JEL Code: C01; C13; C31; Q12

\section{INTRODUCTION}

Globally, agriculture plays a vital role in spurring economic growth, increasing income, enhancing food and nutritional security, as well as overcoming poverty (Yeyo et al., 2014). In much of sub-Saharan African (SSA) countries, the sector remains the main pathway for smallscale farmers contributing to increased income, poverty reduction, and food and nutrition security (World Bank, 2008). In Kenya, agriculture accounts for about $65 \%$ of the total exports, contributes to about $30 \%$ of Gross Domestic Product (GDP), and provides employment opportunities to more than $80 \%$ of the population, therefore, remains a major source of livelihood for about $80 \%$ of the rural populace (Kenya National Bureau of Statistics, KNBS, 2016; KNBS, 2017). Despite being the mainstay of the Kenyan economy, agriculture is constrained with many factors that limit the production levels as well as the quality of marketed products. These constraints include declining farm or agricultural productivity due to adverse effects of climate change, increased pest and weed infestation, adoption of outdated technology and inputs, as well as low and declining soil fertility (Vanlauwe $\boldsymbol{e t}$ al., 2008; Midega et al., 2016). The Government of Kenya (GoK) has been identifying and promoting the development, dissemination, and continual uptake of new and improved agricultural production technologies as a fundamental strategy for mitigating these challenges (GoK, 2012).

In this regard, a number of new and improved agricultural technologies have been developed and effectively disseminated by the Government of Kenya and other Non-Governmental Organizations (NGOs) with the aim of increasing agricultural productivity to meet the demand of the growing population. This also helps in spurring economic growth, arresting environmental degradation, as well as improving the livelihoods of smallscale farmers (Obare et al., 2011; GoK, 2012). These new and improved agricultural technologies are largely promoted in Kenya to ensure the efficient production of major staples, cash, or food crops such as maize (Zea mays L.) and sorghum (Sorghum bicolor L. Moench) (Romney 
et al., 2003). Among these new and improved technologies is an integrated pest and weed management technology known as Push-pull technology (PPT) developed by International Centre of Insect Physiology and Ecology (ICIPE), Kenya Agricultural and Livestock Research Organisation (KALRO) and Rothamsted Research in the United Kingdom (Oswald, 2005). Pushpull technology as an integrated pest and weed management system was invented to address six major constraints affecting maize production in Kenya (Murage et al., 2012; Murage et al., 2015). These maize production constraints are experienced by the majority of small-scale farmers in Kenya, especially in the western region, and they include infestation by lepidopteran stem borers (Busseola fusca or Chilo partellus), parasitic Striga weed (Striga hermonthica), fall armyworm, soil erosion, inadequate fodder, and declining soil fertility (Vanlauwe et al., 2008; Cairns et al., 2013).

Stem borers, fall armyworm, and parasitic Striga weed often constrain cereal production in the southern part of the western region including Homa Bay County, resulting to up to $10-100 \%$ of total grain output loses depending on their biological and nocturnal characteristics, phonological stage at infestation, population density as well as conventional and cultural control practices in place (Kfir et al., 2002; Khan et al., 2008a; Midega et al., 2016). According to Midega et al. (2016) stem borers, fall armyworm, and parasitic Striga weed competes for nutrient and moisture needs, thereby suppressing the growth of maize crops. This results in a severe reduction in the amount of maize output or even total crop damage in severe cases (Khan et al., 2008b). Stem borers, fall armyworm, and parasitic Striga coupled with low and declining soil fertility, soil erosion and other adverse effects of climate change often make countless Kenyans go hungry (Rodenburg et al., 2005). Moreover, controlling these pests and weeds have been a difficult activity for small-scale maize producer in this area largely because of their biological and nocturnal characteristics, availability of impractical and uneconomical recommended control strategies, as well as persistent use of conventional and cultural control practices which have overtime shown minimal and localized success (Pickett $\boldsymbol{e t}$ al., 2008; Midega et al., 2016).

International Centre of Insect Physiology and Ecology (ICIPE, 2018) has largely promoted PPT, as an integrated pest and weed management technology, with the aim of reducing maize and sorghum yield losses due to stem borers, fall armyworm, and parasitic Striga weed infestation. The technology also helps in minimizing agrochemical usage, improving soil fertility and moisture, increasing livestock feeds, as well as lowering the cost of production thereby improving livelihood outcomes of small-scale farmers both at the household and national level (Kfir et al., 2002; Pickett et al., 2008; Khan et al., 2008a; Midega et al., 2016). PPT, therefore, involves intercropping maize with a stemborer moth repellent fodder legume known as desmodium (Desmodium uncinatum). Desmodium applies a stimuli-deterrent diversionary strategy to control cereal stem borers (Cook, Khan, and Pickett, 2007). Again, brachiaria grass or napier grass (Pennisetum purpureum) is cropped around the farm as an attractant trap plant. The mechanism involves the push where desmodium repels stem borers and fall armyworms and suppresses Striga attack. The pull is where napier grass attracts and kills stem borers and fall armyworms (Cook, Khan and Pickett, 2007). Desmodium being legume plant also helps in improving soil fertility and moisture through nitrogen fixation. Desmodium and napier grass also helps in providing fodder and income.

Many studies have been conducted to determine the effect of PPT adoption on household welfare (Vanlauwe et al., 2008; Khan et al., 2008b; DeGroote et al., 2010; Martin, 2010; Murage et al., 2015; Chepchirchir et al., 2016; Ogot et al., 2017). However, the enormous PPT literature, which includes the determinants of PPT adoption decision, intensity, and its impacts on welfare, presents diverse results depending on the location of the study and welfare indicators. Vanlauwe et $\boldsymbol{a l}$. (2008) estimated the economic benefits of four related integrated pest management systems namely traditional maize-bean intercrop, crotalaria-maize rotation, push-pull intercrop, and soybean-maize rotation. They found that the PPT system significantly reduces stem borer damage and Striga emergence from the second season onwards, thereby resulting in higher yields, enhanced food security, and poverty alleviation compared to other systems. In a related study, Khan et al. $\mathbf{( 2 0 0 8 b )}$ used cost-benefit ratio analysis to calculate gross margins and net present values (NPV) of land and labour of PPT against other cropping systems in western Kenya. They reported that maize yields and associated gross margins were significantly higher for PPT farming than other systems. Even though, the results indicated higher production costs and net return to land and labour in the PPT system during first cropping year, a reduction in cost was evidenced from year two of operations onwards in most plots of the studied districts (Gwada, 2019). DeGroote et al. (2010) used marginal effect and discounted partial budget analysis to determine the economic performance of different integrated soil fertility and pest management options in maize production systems in Western Kenya. They added that PPT farming generated the highest income than other options, thereby making it appropriate technology for poverty reduction and food security.

In the light of the foregoing, Martin (2010) conducted a peer-review evaluation in 12 districts of eastern Uganda and western Kenya and found that PPT significantly reduced the smallholder farmers' vulnerability by promoting better and higher maize and sorghum grain yields, reduced soil erosion, increased soil fertility, improved livestock health as well as extra income from diversified sources such as the sale of desmodium and napier fodder. It was added that these benefits have greatly contributed to improved food security, increased well-being, and poverty reduction among those farmers (Martin, 2010). Khan et al. (2011) further reiterated that PPT is an appropriate and effective integrated pest control system as it addresses important cereal production problems as well as increasing maize and sorghum yields from 0.1 to 3.5 tonnes per hectare. They highly recommended PPT for continued food security and poverty reduction among resource-poor farmers. Using 
the marginal rate of return methods, Murage et al. (2015) studied the potential ex-ante effect of climate-smart PPT in Tanzania, Kenya, and Ethiopia with a view to promoting wide-scale dissemination. The results indicated that the marginal rate of return for maize and sorghum were $143.4 \%$ and $109.2 \%$, respectively with an expected improvement in food security and poverty alleviation status among smallholder farmer. A recent study by Chepchirchir et al. (2016) revealed that when the intensity of PPT uptake increases, on average, the probability of a farmer being poor reduces from $47 \%$ to $27 \%$ through improved crop output, farm incomes, and household per capita food consumption expenditure. Ogot et al. (2017) also reported that PPT technology positively impacted the nutritional outcomes of farmers' children. Most of these studies reviewed posited that PPT elevates production, boosts income, and food expenditure thus resulting in higher income, poverty reduction, and better food and nutritional status.

Importantly, it can be said that a lot of literature exists on PPT, however, very little has been documented on the impacts of continual uptake of PPT on livelihood outcomes such as per capita consumption expenditure, household dietary diversity, and poverty reduction especially in Homa Bay County, Kenya. In fact, the previous studies reviewed did not look at the impact of continual uptake of PPT in Homa Bay county. However, the literature reveals that most of the previous studies focused on PPT perception and adoption determinants without taking into consideration factors that greatly influence its continual uptake decision (Gwada, 2019). Again, such studies did not consider the application of propensity score matching as one of the recommended models of eliminating selection bias and heterogeneity when analysing the impact of technology adoption on livelihood outcomes.

This study, therefore, deviates from previous studies and evaluates the effect of continual uptake of PPT as an integrated pest and weed management technology, on livelihood outcomes of small-scale maize producers in Homa Bay County, Kenya. Livelihood outcomes under study are per capita consumption expenditure, household dietary diversity (HDDs), and poverty reduction as these were not given much attention in the previous studies. This study contributes to the existing literature on the impact of agricultural technology adoption by presenting a micro perspective on the effect of continual uptake of PPT. Evaluating the effect of continual uptake of PPT helps in providing feedback to the researchers, as well as in setting priorities. It also guides governments, NGOs, policymakers, and those involved in the dissemination of integrated pest and weed management technologies to have a better glimpse of the way new technologies can be assimilated and disseminated among small-scale maize farmers for continual uptake. The study also provides evidence that maize farmers benefit from continual PPT uptake, thus improving the contribution of the agricultural sector to the country's economy to meet its broader development goals such as Sustainable Development Goals (Goal 1 of ensuring no poverty, goal 2 of ensuring zero hunger, goal 10 of ensuring reduced inequality, and goal 12 of ensuring responsible consumption and production) and the Big Four agenda (agenda 2 of ensuring $100 \%$ food security and nutritional commitment) (Gwada, 2019).

\section{DATA AND METHODS}

\section{Study Area}

This study was conducted in Homa-Bay County. Homa Bay County is one of the counties in the western region of Kenya. The county has eight sub-counties namely Ndhiwa, Suba North, Kasipul, Homa Bay Town, Karachuonyo, Suba South, Kabondo-Kasipul, and Rangwe. The choice of Homa-Bay county was motivated by the fact that it has the majority of the farmers practicing maize production as part of their livelihood (GoK, 2018). Again, it is one of the counties along the shore of Lake Victoria where stem borer, fall armyworm, Striga weed, climate change, and low and declining soil fertility are major problems to sustainable maize production. Lastly, it is where PPT has been widely promoted or disseminated by ICIPE and government of Kenya for the effective control of Striga weed, fall armyworm, stem borers, and declining soil fertility (Gwada, 2019). Homa Bay county covers approximately 3183.3 square kilometres with a population of 963,794 people, and a population density of 117 persons per square kilometre (KNBS, 2009). The altitude of the county ranges from 1134 to 1230 meters above the sea level and located between latitude $0^{\circ} 40^{\prime}$ $60.00^{\prime \prime}$ North and a longitude of $34^{\circ} 27^{\prime} 0.00^{\prime \prime}$ East. Homa Bay county experiences a bimodal rainfall pattern; where the long rains occur between March and July and short rains occurring between August and October. Annual rainfall in the study area ranges from 250 to $1200 \mathrm{~mm}$ per year while the temperature ranges from 26 to 34 degrees Celsius. Agriculture is the main economic activity in the area. The county is characterized by well-drained, rich, and fertile soils that support the production of major crops like maize, sorghum, beans, and millet.

\section{Sampling and Data Collection}

Since the population was known, the study sample size of 240 respondents was determined using proportionate to the number of households sampling methodology as propounded by Kothari (2004). Based on quantitative research design, a sample of 240 respondents was randomly selected from a population of small-scale maize producers in Homa Bay County using a multistage sampling technique. Primary data were collected through face to face interviews, using a pretested semi-structured questionnaire administered by a group of trained enumerators. This was divided equally between PPT adopters (dis-adopters included), and non-adopters in the county to achieve perfect compliance Kothari (2004). However, 2 observations were excluded from the analysis because they were regarded as outliers.

\section{Econometric Model Specification}

Impact evaluation can be done for both experimental (randomized) and non-experimental programs. For experimental studies, impact evaluation for technology uptake can be done by simply comparing individual welfare outcomes of adopters, dis-adopters, and non- 
adopters to compute the Average Treatment Effect (ATT) (Becker and Ichino, 2002). However, many integrated pest and weed management technologies such as PPT are not randomly assigned, in that farmers' decision to adopt or not and to dis-adopt or not depend on the amount of information they have (Dehejia and Wahba, 2002). This brings the problem of a counterfactual outcome where it is difficult to determine the welfare outcomes of farmers who adopted the technology had they not adopted that technology (Dehejia and Wahba, 2002). Previous studies have refuted the use of ordinal least squares (OLS) model in impact evaluations since it generates biased estimates by its assumption that adoption or dis-adoption of agricultural technology is determined exogenously, and yet it is potentially endogenous, voluntary and depends on individual self-selection and expected benefits which systematically differs across individuals (Heckman et al., 1998; Wooldridge, 2005).

This results in the problem of self-selection that makes it difficult to directly compare the welfare outcomes of adopters, dis-adopters, and non-adopter. Again, there are some unobserved individual, farm, and institutional characteristics that may affect adoption and dis-adoption as well as the welfare variable, thus resulting in inconsistent estimates, due to endogeneity problem (Smith and Todd, 2005). It is, therefore, important to apply an econometric model that eliminates both endogeneity and selection bias while evaluating the impact of technology adoption on welfare outcomes such as per capita consumption expenditure (Heckman et $\boldsymbol{a l}$., 1998). This motivated the use of propensity score matching (PSM) model to control for both endogeneity and sample selection bias between PPT continued uptake decision and other explanatory variables. This is known as confoundedness assumption. PSM is based on the expected utility theory which states that a rational decision maker will only choose a decision with the highest expected utility. Again, PSM is recommended because it does not depend on distributional assumptions and functional form, makes it easier to compare the observed outcomes of continual PPT adopters with those of counterfactual non-adopters, and finally works well with a single cross-sectional dataset like the case of the proposed study (Heckman et al., 1998).

PSM method helps in matching the observations of PPT continued users and non-adopters, based on predicted propensity score or probability of adopting PPT continuously. This is done by creating the conditions of a randomized experiment for evaluating the causal effect just like in a controlled experiment situation (Dehejia and Wahba, 2002). This ensured that all observational characteristics are controlled thereby making the continual PPT adoption or dis-adoption a random assignment and uncorrelated with the outcome variables which in this case are per capita consumption expenditure, household dietary diversity score, and poverty indices (Smith and Todd, 2005). To arrive at robust results, chances of systematic difference between the outcomes of PPT continued users and non-adopters that are caused by the selection of unmeasured characteristics were eliminated when conditioning as shown below (Smith and Todd, 2005).
Let $A$ denotes a dummy variable for PPT continual uptake status where $A_{i}=1$ is if $i^{\text {th }}$ individual adopted PPT continuously, and $A_{i}=0$ is otherwise or non-adoption. In addition, let $Y_{1 i}$ and $Y_{2 i}$ denote expected observed livelihood outcomes for continual PPT adopters and nonadopter, respectively. Then treatment effect, $T E$ is expressed by Eq. (1).

$T E=Y_{1 i}-Y_{2 i}$

Eq. 1 gives the impact or treatment effect of PPT continued uptake on the $i^{\text {th }}$ individual. Since we only observe Eq. (2).

$Y_{i}=A_{i} Y_{1 i}+\left(1-A_{i}\right) Y_{2 i}$

Rather than $Y_{1 i}$ and $Y_{2 i}$ for the same farmer, we find it difficult to arrive at the treatment effect for every farmer. Therefore, we can only calculate the average effect of treatment on the treated, ATT as shown in Eq. (3) (Becker and Ichino, 2002).

$A T T=E\left(Y_{1 i}-Y_{2 i} \mid A_{i}=1\right)$

According to Rosenbaum and Rubin (1983) the propensity scores for continued uptake are estimated as shown in Eq. (4).

$\operatorname{Prob}(X)=\operatorname{Prob}\left(A_{i}=1 \mid X\right)$

Depending on the conditional independence assumptions (Eq. 5),

$Y_{1 i}, Y_{2 i} \perp \mathrm{A} \mid X$

the potential livelihood outcomes are independent of technology continued uptake given $X$ which represented vector of the independent variable, which implies Eq. 6-7.

$$
\begin{aligned}
& E\left(Y_{2 i} \mid A=1, \operatorname{Prob}(X)\right)=E\left(Y_{2 i} \mid A=0, \operatorname{Prob}(X)\right) \\
& \text { and } \\
& 0<\operatorname{Prob}(X)>1
\end{aligned}
$$

For all $X$, there is a positive likelihood of either continuously adopting PPT $(A=1)$ or not adopting $(A=$ $0)$ as this guarantees every PPT continued user a counterpart in the non-adopter population. Therefore, resulting ATT can be estimated as Eq. 8-10.

$$
\begin{aligned}
& A T T=E\left(Y_{1 i}-Y_{2 i} \mid A=1\right) \\
& A T T=E\left[E\left(Y_{1 i}-Y_{2 i} \mid A_{i}=1, \operatorname{Prob}(X)\right)\right] \\
& A T T=E\left[E\left(Y_{1 i} \mid A_{i}=1, \operatorname{Prob}(X)\right)-E\left[Y_{2 i} \mid A_{i}=\right.\right. \\
& 0, \operatorname{Prob}(X))]
\end{aligned}
$$

Since propensity scores or probabilities are continuous variables, there is no way of getting PPT continued user with the same score to be used as counterfactual, as this renders Eq. 9 insufficient in computing average treatment effect (Smith and Todd, 2005). Therefore, it is important to apply more than two matching methods to help in checking the robustness of 
result estimates. This study, therefore, applied 3:1 nearest neighbour matching (NNM) and kernel matching (KE) techniques to ascertain the consistency and robustness of impact estimates. Therefore, using a STATA software, a propensity score matching method was used to assess and compare the impact or Average Treatment Effect of PPT continued uptake on smallholder per capita consumption expenditure, household dietary diversity score (HDDs), and poverty status. Poverty was measured by the poverty gap index and poverty severity index. Household dietary diversity score was used to measure dietary diversity as nutritional outcomes based on the number of food groups households consumed. It accurately reflects the diversity of macro and micronutrient intake (Kennedy et al., 2011). HDDs, therefore, had 0-12 scores for 12 food groups consumed by households based on 24hr-recall. These include cereals, fish and seafood, root and tubers, pulses, legumes or nuts, vegetables, milk and milk products, fruits, oil or fats, meat, poultry, or offal, sugar or honey, eggs, and miscellaneous. These food groups were added to give HDDs for each household.

To evaluate poverty levels among the households, this study adopted the Foster, Greer, and Thorbecke (FGT) poverty index (Foster, Greer and Thorbecke, 1984). FGT poverty index uses the poverty line as the threshold level of wellbeing that distinguishes poor individuals from non-poor individuals, to compute some aggregate poverty measures. This study adopted the mean consumption expenditure of Kenyan Shillings (KES). 154.28 as the poverty line. Foster, Greer, and Thorbecke's poverty index is measured as shown in Eq. (11).

$P_{j}=\frac{1}{N} \sum_{i=1}^{Q}\left(\frac{Z-Y_{i}}{Z}\right) a$

Where: $P_{j}$ represents Foster, Greer, and Thorbecke poverty indices ranging between 0 and $1 . N$ is the total number of farmers in the study, $q$ is the number of farmers leaving below the poverty line, $Z$ is the national poverty line or mean consumption expenditure, and $Y_{i}$ is household per capita expenditure on food and non-food items of the $i^{\text {th }}$ individual. Therefore, the poverty status of the respondents was divided into three indicators as follows. When $a=0, P_{0}$ gives the headcount index measuring the incidence of poverty. When $a=1, P_{1}$ gives the poverty gap index measuring the depth of poverty, and finally when $a=2, P_{2}$ gives the poverty squared poverty gap index measuring the severity of poverty among the household. Description of dependent and independent variables and their expected signs are provided in Table 1.

\section{RESULTS AND DISCUSSION}

\section{Descriptive Statistics of the dependent and independent variables}

Descriptive statistics of continuous and categorical variables used in the analysis are presented in Tables 2 and 3 , respectively. Maize producers were classified into three groups namely; PPT continuous users $(n=74)$, disadopters $(n=49)$, and non-adopters $(n=115)$. To test for significant differences among variables across the PPT farmer categories, ANOVA/F-test and a Chi-square test were used for continuous and categorical variables, respectively. In terms of age of the household head, PPT continuous users were significantly older (about 55 years) with more years of education (11) compared to PPT disadopters and non-adopters who had a mean age of 51 and 50 years with approximately 10 and 7 years of schooling, respectively. Significantly, PPT continuous users had a higher mean household size of about 8 members with approximately 2.97 acres of land compared to PPT disadopters and dis-adopters who had roughly 6 and 5 family members with 1.52 and 1.82 acres of land, respectively (Gwada, 2019). The results revealed that there was a statistically significant difference in the mean walking distance to the nearest administrative center across the groups. On average, PPT continuous users had to travel approximately 37.32 minutes to the nearest administration center compared to 56.22 minutes travelled by the PPT dis-adopters and 69.29 minutes travelled by non- adopters. This implies that PPT continuous users were taking significantly lesser minutes to reach the nearest administrative center compared to PPT dis-adopters and non-adopters. By implication, as the distance to the most adjacent administrative center decreases, there is the possibility of reduced transaction costs associated with ease of accessing extension information and credit markets, thus increasing the likelihood of adoption and continued use of new technologies by a household (Awotide, Karimov and Diagne, 2016). Again, PPT continuous users had a significantly higher number of group memberships (4 groups) compared to non-adopters ( 2 groups) and dis-adopters ( 2 groups). On average, PPT continuous users had significantly higher tropical livestock units (7.42) compared to non-adopters (3.86) and dis-adopters (4.34). Tropical livestock unit (TLU) was measured using FAO (2015) guidelines. Similarly, PPT continuous users were earning significantly higher annual off-farm income of KES. 245,869.95 (2458.69USD) compared to non-adopters and dis-adopters earning KES. 130,782.51 (1307.82 USD) and KES. 106,519.37 (1065.19 USD) per annum, respectively.

The results in Table 3 indicated that the majority $(71.43 \%)$ in the whole sample were married households (Gwada, 2019). Similarly, the proportions of married families for PPT continuous users, dis-adopters, and nonadopters were $75.68 \%, 71.43 \%$, and $68.70 \%$, respectively. The sampled households composed of both female and male heads of households. Overall, the majority $(64.71 \%)$ were male-headed households while $35.29 \%$ were headed by females. The male-headed household's proportion for PPT continuous users, dis-adopters and non-adopters were $82.43 \%, 63.27 \%$, and $53.91 \%$, while female-headed household's proportion for the PPT continuous user, disadopters and non-adopters were $17.57 \%, 36.73 \%$, and $46.09 \%$, respectively. This shows that female-headed households were significantly fewer than male-headed households for each PPT uptake category (Gwada, 2019). Results significantly revealed that PPT continuous users recorded the highest percentage $(86.49 \%)$ of those farmers owning land with title deeds compared to dis-adopters (46.94\%) and non-adopters $(29.57 \%)$. 
Descriptive statistics revealed that the majority of PPT continuer users $(89.19 \%)$ significantly perceive stem borer and armyworm as a major problem compared to PPT disadopter (77.55\%) and non-adopters (45.22). Similarly, the majority of PPT continuous users $(89.19 \%)$ significantly perceive stem Striga weed as a major problem compared to dis-adopter $(77.55 \%)$ and non-adopters $(40.87 \%)$. Since PPT is designed to effectively control Striga weed, stem borers, and fall armyworms, farmers' experience on these constraints especially in the last cropping seasons could influence its continual uptake.

\section{Econometric estimation of the effect of continued uptake of push-pull technology on the livelihood outcomes Selection of Livelihood Outcome Variables}

Table 4 shows one-way ANOVA and Chi-Square results for selected livelihood outcomes. Results revealed a statistically significant difference in household per capita consumption expenditure per day across the PPT uptake categories. The average household per capita consumption expenditure per day for the entire sample was KES. 154.28/1.54 USD. Continuous users of PPT recorded a statistically significantly higher average household per capita consumption expenditure per day of KES. 196.16/1.96 USD followed by non-adopters (KES. 141.57/1.42 USD), and lastly dis-adopters (KES. 119.88/ 1.20 USD) (Gwada, 2019). This is attributed to more income from PPT production used in purchasing various goods. These results are consistent with those from a study by Chepchirchir et al. (2016) on the impact of intensity of PPT uptake on household welfare. They found a higher per capita consumption expenditure among PPT adopters than non-adopters in eastern Uganda.

Overall, the majority $(62.18 \%)$ in the entire sample were living below the poverty line with only $37.82 \%$ of the households living above the poverty line as shown in Table 4. The proportions of households living above the poverty line for PPT continuous users, dis-adopters, and non-adopters were $60.81 \%, 14.29 \%$, and $33.04 \%$, respectively. Again, the proportions of households living below the poverty line for PPT continuous users, disadopters, and non-adopters were $39.19 \%, 85.71 \%$, and 66.96 , respectively. This implies that the majority of the continuous users were significantly living above poverty live compared to other PPT adoption categories. In terms of the poverty gap, there was a statistically significant difference across PPT adoption categories (Gwada, 2019).

The poverty gap for the entire sample was 0.22 , with a lower depth of poverty among PPT continuous users (0.09), followed by non-adopters $(0.27)$ and lastly disadopters (0.30). In other words, the depth of poverty was statistically significantly lower among PPT continuous users compared to non-adopters. Lower depth of poverty witnessed among PPT continuous users compared to disadopter or non-adopters could be linked to the perceived benefits of PPT in terms of improved production or income received from its diversified outcomes. The severity of poverty for the entire sample was 0.09 , with significantly lower severity among PPT continuous users (0.03), followed by non-adopters $(0.12)$ and dis-adopters (0.12) (Gwada, 2019).
One-way ANOVA results revealed that there was a statistically significant difference in Household Dietary Diversity Score across the farmer groups. On average, PPT continuous users recorded significantly a higher Household Dietary Diversity Score of 10.38, followed by dis-adopters (6.67) and lastly non-adopters (6.39). This implies that on average PPT continuous users have higher access to quality food diet compared to non-adopters and dis-adopters. This is attributed to more income from PPT production that can be used in purchasing various food groups. In a related study, Ogot et al. (2017) opined that PPT as an agricultural intervention has improved the nutritional status of farmers' children in western Kenya.

\section{Selection of Variables and Determination of Propensity Scores}

In order to measure the causal effect of PPT continued uptake on selected livelihood outcomes, PPT dis-adopters were excluded, and another a probit model adopted to estimate the probability of continued PPT uptake. Based on the conditional independence assumption, only regressors that are significant determinants of livelihood outcomes, as well as PPT continued uptake, were selected. First, the variance inflation factor (VIF) was performed to examine the presence of multicollinearity among independent variables, and results are presented in Table 5. Result revealed that VIF values of individual variables range from 1.22 to 2.03 with mean VIF of 1.61. This presents that no collinearity existed between these independent variables since all VIF values were below the recommended value of 10 (Greene, 2000). The results of the Breusch-Pagan test for heteroscedasticity $\left(X^{2}=1.92\right.$, $p=0.1658$ ) showed that the model was free from heteroscedasticity problems, as the null hypothesis for homoscedasticity (constant variance) was not rejected.

Table 6 presents the associated estimates of the probit model. Table 6 shows a log-likelihood ratio of -47.35 indicating how the model quickly converges. The likelihood ratio chi-square statistic $\left(\mathrm{LR} \mathrm{chi}^{2}(13)=158.34\right.$, $p=0.000)$ and Pseudo $\mathrm{R}^{2}$ of 0.626 show that the model wholly and significantly fits the data well, and in that the decision to continuously uptake PPT were attributed to the explanatory variables considered in the probit model. This also shows that the combination of explanatory variables meets the balance requirement. Table 6 also presents information about some of the factors influencing farmers' decisions to continuously uptake PPT where the explained variable takes the value of one (1) if the farmer adopted and still practicing PPT, and zero (0) if the farmer completely never adopter. The results of the probit model showed that age of the household head, education level of household head, total farm size owned, type of land ownership, perception on Striga weed severity, perception on stem borer/fall armyworm severity, and distance to the nearest administrative center has a statistically significant influence on continued uptake of PPT as shown in Table 6.

The age of the household head was found to be a positive and significant determinant of continued uptake of PPT at a $10 \%$ level. An increase in the age of the household head raises the probability of adopting PPT continuously. 
Table 1: Description of dependent and independent variables and their expected signs

\begin{tabular}{|c|c|c|c|c|}
\hline Variables & Description & $\begin{array}{l}\text { Variable } \\
\text { Type }\end{array}$ & Measurement & $\begin{array}{l}\text { Expected } \\
\text { Sign }\end{array}$ \\
\hline \multicolumn{5}{|l|}{ Dependent Variables } \\
\hline PPT adoption & If the farmer adopted PPT or not & Dummy & $1=$ Yes, $0=$ No & None \\
\hline PPT continual adoption & If the farmer continues with PPT adoption or dis-adopted & Dummy & $1=\mathrm{Yes}, 0=\mathrm{No}$ & None \\
\hline Per capita consumption expenditure & Annual household expenditure on food and non-food items & Continuous & Kenyan Shillings (KES)/ USD & None \\
\hline Poverty gap index & A measure representing poverty intensity of a household & Continuous & Number & None \\
\hline Squared Poverty gap index & A measure of severity of household poverty & Continuous & Number & None \\
\hline HDDs & Household dietary diversity score & Continuous & Number & None \\
\hline \multicolumn{5}{|l|}{ Independent Variables } \\
\hline Age & Age of the household head in years & Continuous & Years & \pm \\
\hline Gender & Gender of the household head & Binary & $1=$ Male, $0=$ Female & \pm \\
\hline Marital status & Marital Status of the household head & Binary & $1=$ Married, $0=$ No spouse & \pm \\
\hline Education level & Years of schooling of the household head & Continuous & Number & \pm \\
\hline Log off-farm income & Natural logarithm of total income from off-farm sources & Continuous & Number & \pm \\
\hline Household size & Number of the person within a household & Continuous & Number & \pm \\
\hline Perception of Striga weed severity & Perception of Striga severity & Categorical & $\begin{array}{l}1=\text { Major problem, } 0=\text { not } a \\
\text { problem }\end{array}$ & \pm \\
\hline $\begin{array}{l}\text { Perception of stem borer/ armyworm } \\
\text { severity }\end{array}$ & Perception of stem borer/ armyworm severity & Categorical & $\begin{array}{l}1=\text { Major problem, } 0=\text { not } a \\
\text { problem }\end{array}$ & \pm \\
\hline Group membership & Number of farmer groups & Continuous & Number & \pm \\
\hline $\begin{array}{l}\text { Distance to the nearest administrative } \\
\text { center }\end{array}$ & Distance to the nearest administration center & Continuous & Walking minutes & \pm \\
\hline Land ownership & Type of land ownership & Binary & $1=$ Owned with title, $0=$ No title & \pm \\
\hline Total farm size owned & Total land size owned & Continuous & Acres & \pm \\
\hline Tropical livestock unit & Total Livestock Unit & Continuous & Units & \pm \\
\hline
\end{tabular}


Table 1: Descriptive statistics for continuous variables

\begin{tabular}{|c|c|c|c|c|c|c|}
\hline Variables & $\begin{array}{l}\text { Push-Pull Techi } \\
\text { Overall sample } \\
\text { n=238 } \\
\text { Mean/std dev }\end{array}$ & $\begin{array}{l}\text { hology Uptake S } \\
\text { All Adopters } \\
n=123 \\
\text { Mean/std dev }\end{array}$ & $\begin{array}{l}\text { tatus } \\
\text { Continuous Users } \\
\mathrm{n}=74 \\
\text { Mean/std dev }\end{array}$ & $\begin{array}{l}\text { Dis-adopters } \\
\mathrm{n}=49 \\
\text { Mean/std dev }\end{array}$ & $\begin{array}{l}\text { Non- adopters } \\
\mathrm{n}=115 \\
\text { Mean/std dev }\end{array}$ & Statistics \\
\hline \multirow[t]{2}{*}{ Age of household head (Years) } & 51.79 & 53.52 & 54.86 & 51.48 & 49.93 & $5.83^{* * *}$ \\
\hline & $(9.92)$ & $(10.33)$ & $(10.44)$ & $(9.91)$ & $(9.14)$ & \\
\hline \multirow[t]{2}{*}{ Education level (Years) } & 8.73 & 10.43 & 10.82 & 9.84 & 6.91 & $31.61^{* * *}$ \\
\hline & $(3.90)$ & $(3.19)$ & $(3.02)$ & $(3.37)$ & $(3.78)$ & \\
\hline \multirow[t]{2}{*}{ Household size (number) } & 7.03 & 7.63 & 7.84 & 6.33 & 5.38 & $4.59^{* *}$ \\
\hline & $(3.56)$ & $(3.47)$ & $(3.45)$ & $(3.51)$ & $(3.13)$ & \\
\hline \multirow[t]{2}{*}{ Total farm size owned (Minutes) } & 2.12 & 2.39 & 2.97 & 1.52 & 1.82 & $27.31^{* * * *}$ \\
\hline & $(1.35)$ & $(1.37)$ & $(1.34)$ & $(0.89)$ & $(1.26)$ & \\
\hline \multirow[t]{2}{*}{ Distance to the nearest administrative center (walking minutes) } & 56.66 & 44.85 & 37.32 & 56.22 & 69.29 & $11.23^{* * *}$ \\
\hline & $(47.17)$ & $(43.16)$ & $(33.39)$ & $(53.10)$ & (48.17) & \\
\hline \multirow[t]{2}{*}{ Group membership (number of groups) } & 2.89 & 3.48 & 3.92 & 2.82 & 2.25 & $10.86^{* * *}$ \\
\hline & $(2.50)$ & $(2.51)$ & $(2.49)$ & $(2.42)$ & $(2.34)$ & \\
\hline \multirow[t]{2}{*}{ Tropical livestock units ${ }^{\text {a }}$} & 5.06 & 6.19 & 7.42 & 4.34 & 3.86 & $12.76^{* * *}$ \\
\hline & $(5.10)$ & (5.87) & $(6.07)$ & $(5.06)$ & (3.80) & \\
\hline \multirow[t]{2}{*}{ Off-farm income (USD) } & 1615.70 & 1903.56 & 2458.69 & 1065.19 & 1307.82 & $17.29^{* * * *}$ \\
\hline & $(1605.27)$ & $(1882.33)$ & $(2219.81)$ & $(564.80)$ & $(1174.88)$ & \\
\hline
\end{tabular}

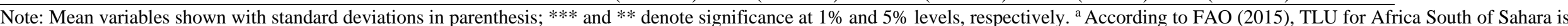
typically taken to be equivalent to: Cattle $=0.50$, sheep=0.10, Goat $=0.10$, Pigs $=0.25$, Asses $=0.50$, Horses $=0.50$, Mules $=0.60$, Camels $=0.70$, or Chicken $=0.01$. 
Table 3: Descriptive statistics for categorical variables

Push-Pull Technology Uptake Status
Overall Sample All Adopters Continuous Users Dis-adopters Non-adopters Statistic n=238 n=123 n=74 n=49 n=115

Variables Freq Percent Freq Percent Freq Percent Freq Percent Freq Percent Chi ${ }^{2}$-test

Gender of household head (\%)

Female

$\begin{array}{lllllllllll}84 & 35.29 & 31 & 25.20 & 13 & 17.57 & 18 & 36.73 & 53 & 46.09 & 16.09 * * *\end{array}$

Male

\begin{tabular}{ccccccccccc}
84 & 35.29 & 31 & 25.20 & 13 & 17.57 & 18 & 36.73 & 53 & 46.09 & $16.09 * * *$ \\
154 & 64.71 & 92 & 74.80 & 62 & 82.43 & 31 & 63.27 & 62 & 53.91 & \\
& & & & & & & & & & \\
170 & 71.43 & 91 & 78.98 & 56 & 75.68 & 35 & 71.43 & 79 & 68.70 & 6.41 \\
68 & 28.57 & 32 & 21.02 & 18 & 24.32 & 14 & 28.17 & 36 & 31.30 & \\
& & & & & & & & & & \\
87 & 36.55 & 19 & 15.45 & 8 & 10.81 & 11 & 22.45 & 68 & 59.13 & $68.22^{* * *}$ \\
151 & 63.45 & 104 & 84.55 & 66 & 89.19 & 38 & 77.55 & 47 & 40.87 & \\
& & & & & & & & & & \\
82 & 34.45 & 19 & 15.45 & 8 & 10.81 & 11 & 22.45 & 63 & 54.78 & $68.22^{* * *}$ \\
156 & 65.55 & 104 & 84.55 & 66 & 89.19 & 38 & 77.55 & 52 & 45.22 & \\
& & & & & & & & & & \\
117 & 49.16 & 36 & 29.27 & 10 & 13.51 & 26 & 53.06 & 81 & 70.43 & $58.75^{* * *}$ \\
121 & 50.84 & 87 & 70.73 & 84 & 86.49 & 23 & 46.94 & 34 & 29.57 & \\
\hline
\end{tabular}

Married

No spouse

Perception of Striga weed severity (\%)

Not a problem

Major problem

Perception of stem borer/armyworm severity (\%)

Not a problem

Major problem

Land tenure $(\%)$

No title

$\begin{array}{llllllllll}121 & 50.84 & 87 & 70.73 & 84 & 86.49 & 23 & 46.94 & 34 & 29.57\end{array}$

Note: $* * *$ denote significance at $1 \%$ levels.

Table 4: Descriptive statistics on selected livelihood outcomes

\begin{tabular}{|c|c|c|c|c|c|c|}
\hline \multirow[b]{3}{*}{ Variables } & \multirow{3}{*}{$\begin{array}{l}\text { Overall sample } \\
n=238 \\
\text { Mean/std. dev. }\end{array}$} & \multicolumn{3}{|c|}{ Push-pull Technology Uptake Status } & \multirow{3}{*}{$\begin{array}{l}\text { Non- adopters } \\
n=115 \\
\text { Mean/std. dev. }\end{array}$} & \multirow[b]{2}{*}{ Statistics } \\
\hline & & $\begin{array}{l}\text { All Adopters } \\
n=123\end{array}$ & $\begin{array}{l}\text { Continuous Users } \\
n=74\end{array}$ & $\begin{array}{l}\text { Dis-adopters } \\
n=49\end{array}$ & & \\
\hline & & Mean/std. dev. & $\begin{array}{l}\text { Mean/std. } \\
\text { dev. }\end{array}$ & Mean/std. dev. & & $\begin{array}{l}\text { F-test/ } \mathrm{Chi}^{2}- \\
\text { test }\end{array}$ \\
\hline $\begin{array}{l}\text { Per Capita Consumption Expenditure per } \\
\text { Day (USD) }\end{array}$ & $1.54(0.91)$ & $1.66(0.91)$ & $1.96(0.91)$ & $1.20(0.71)$ & $1.42(0.90)$ & $13.96^{* * *}$ \\
\hline \multicolumn{7}{|l|}{ Headcount Ratio $(\%)$} \\
\hline Above the poverty line & 37.82 & 42.28 & 60.81 & 14.29 & 33.04 & $29.29 * * *$ \\
\hline Poverty gap (Depth of Poverty) & $0.22(0.20)$ & $0.17(0.10)$ & $0.09(0.15)$ & $0.30(0.19)$ & $.27(0.23)$ & $22.68 * * *$ \\
\hline Squared Poverty Gap (Severity of poverty) & $0.09(0.12)$ & $0.07(0.10)$ & $0.03(0.08)$ & $0.12(0.11)$ & $0.12(0.13)$ & $16.20 * * *$ \\
\hline Household Dietary Diversity Score & $7.69(2.53)$ & $8.90(2.36)$ & $10.38(1.24)$ & $6.67(1.84)$ & $6.39(2.02)$ & $122.83 * * *$ \\
\hline
\end{tabular}

Note: *** denote significance at $1 \%$ level.; Standard deviations in parenthesis. 
Table 5: Multicollinearity diagnosis results of variance inflation factor (VIF)

\begin{tabular}{ll}
\hline Variable & VIF \\
\hline Age of household head & 1.46 \\
Gender & 1.50 \\
Marital status & 1.27 \\
Education level & 1.76 \\
Household size & 1.58 \\
Natural logarithm of off-farm income & 1.59 \\
Total farm size owned & 2.03 \\
Tropical livestock unit & 2.03 \\
Land ownership & 1.45 \\
Perception of Striga weed severity & 1.86 \\
Perception of stem borer/fall armyworm severity & 1.59 \\
Number of farmer groups & 1.54 \\
Distance to the nearest administrative center & 1.22 \\
Mean VIF & 1.61 \\
\hline
\end{tabular}

Table 6: Results of probit estimation of propensity scores

\begin{tabular}{lrrr}
\hline Variables & Coefficient & Standard Error & z-Value \\
\hline Age of household head & 0.033 & 0.019 & $1.74 *$ \\
Gender & 0.372 & 0.413 & 0.9 \\
Household head Marital status & -0.549 & 0.427 & -1.29 \\
Education level & 0.191 & 0.054 & $3.55^{* * *}$ \\
Natural logarithm of off-farm income & 0.0489 & 0.233 & 0.21 \\
Household size & -0.023 & 0.058 & -0.39 \\
Tropical livestock unit & 0.034 & 0.042 & 0.82 \\
Total farm size owned & 0.321 & 0.152 & $2.11^{* *}$ \\
Land ownership & 1.042 & 0.327 & $3.18^{* * *}$ \\
Perception of Striga weed severity & 0.298 & 0.194 & $1.53^{*}$ \\
Perception of stem borer/fall armyworm severity & 0.64 & 0.197 & $3.24^{* * *}$ \\
Distance to the nearest administrative center & -0.013 & 0.004 & $-3.29 * * *$ \\
Number of farmer groups & -0.08 & 0.075 & -1.06 \\
Constant & -5.687 & 2.788 & $-2.04 * *$ \\
\hline
\end{tabular}

Note: Number of observation $=189 ; \log$-likelihood $=-47.35 ; \log$-likelihood $\chi^{2}(13)=158.34$, Breusch-Pagan test for heteroscedasticity: $\mathrm{X}^{2}=1.92, p=0.1658$. Prob $>\chi^{2}=0.000 ;$ Pseudo $\mathrm{R}^{2}=0.626 ; * * *$,

$* *$ and $*$ denote significant at $1 \%, 5 \%$ and $10 \%$ levels, respectively. 
This is attributable to the fact that older farmers have high accumulated knowledge and farming experience obtained from years of experimentation thus able to continuously adopt a technology. Again, older household heads have larger household size, and higher capital accumulation to continuously adopt labour and capital intensive technology like PPT. Onyenweaku et al. (2010) also reported a similar positive relationship between farmers' age and continuous uptake of agricultural technologies. Continuous uptake of PPT was also positively and significantly influenced by the education level of the household head at a $1 \%$ level. A higher level of education increases the probability of adopting PPT continuously. Education helps farmers in making better decisions regarding continuously technology adoption. Educated farmers are well informed and are able to search, consolidate, and interpret agricultural knowledge as well as extension information related to agricultural technology adoption. These results are consistent with the findings by Awotide et al. (2016) and Onyeneke, 2017).

Continuous uptake of PPT was significantly and positively influenced by the total size of land owned by farmers at a 5\% level. By implications, farmers who own a large tract of land are more likely to uptake PPT continuously. This is attributable to the fact that farmers who own a large tract of land have higher levels of land use diversification due to low conflicts and competition on possible uses of land, thus able to adopt a technology continuously. Land tenure had a positive and statistically significant influence on the continuous uptake of PPT at a $1 \%$ level. That is, farmers who own their land with title deeds are more likely to adopt PPT continuous than those owning land without titles. This is attributable to the fact that better land tenancy provides long-term security which raises the probability that farmers will adopt and continue using agricultural technologies, which require long-term investment to capture their returns such as PPT. Kpadonou et al. (2017) also reported similar results that higher levels of land ownership and user right security positively influence investments in long-term projects such as forest conservation projects.

The influence of perception on Striga weed and stem borer/fall armyworm severity on continued uptake of PPT was also found to be positive and significant at $10 \%$ and $1 \%$, respectively. In other words, farmers who still perceive Striga weed, stem borers, and fall armyworm as major problems to maize production are more likely to uptake PPT continuously as opposed to those who perceived them as a non-problem. Since PPT is an integrated pest and weed technology designed to control Striga weed, fall armyworm, and stem borer, farmers' who still face these constraints on their farms are more likely to continuously use PPT. Murage et al. (2015) also found a similar result that farmers who perceived an agricultural problem as severe would be more willing to adopt any technology available to combat it, than those who perceived it as less severe. Finally, the distance from the farm to the administrative center negatively and significantly influenced PPT's continual uptake decision at a $1 \%$ level. This inverse relationship implies that, as the distance to the nearest administrative center decreases, there is possibility of reduced transaction costs associated with accessing extension information, input and output markets, as well as credit markets, thus increasing the likelihood of continual use of agricultural technologies like PPT (Awotide et al., 2016).

\section{Balancing Test and Common Support Determination}

To determine the effect of continual PPT uptake, it is essential to consider the fact that PPT continuous users might also have realized a higher level of livelihood outcomes, even if they had not continuously practiced PPT. As a result, the study adopted propensity score matching techniques that account for all observable factors or characteristics to distinguish the intrinsic effect of PPT continued uptake on household livelihood outcomes. Therefore, the "balance test" was performed to balance the distribution of the relevant covariates between PPT continuous users and non-adopters, before and after matching. The common support condition or the overlap was checked using a line graph that presents the propensity score distribution (x-axis) between PPT continuous user (treated) and non-adopters (untreated). The region of common support ranged from 0 to 0.999 as presented in Figure 1. Common support condition helps in ensuring that all combination of observed household characteristics in the treatment and control group are matched. Looking at the propensity score distributions based on the common support region and the overlaps, it can be seen that most of the scores between the PPT continuous users' category and non-adopters' category were within the region of common support. This is also evidenced by more overlaps between the treated and untreated groups. As a consequence, only a few observations were rejected from the analysis; hence a good match was obtained.

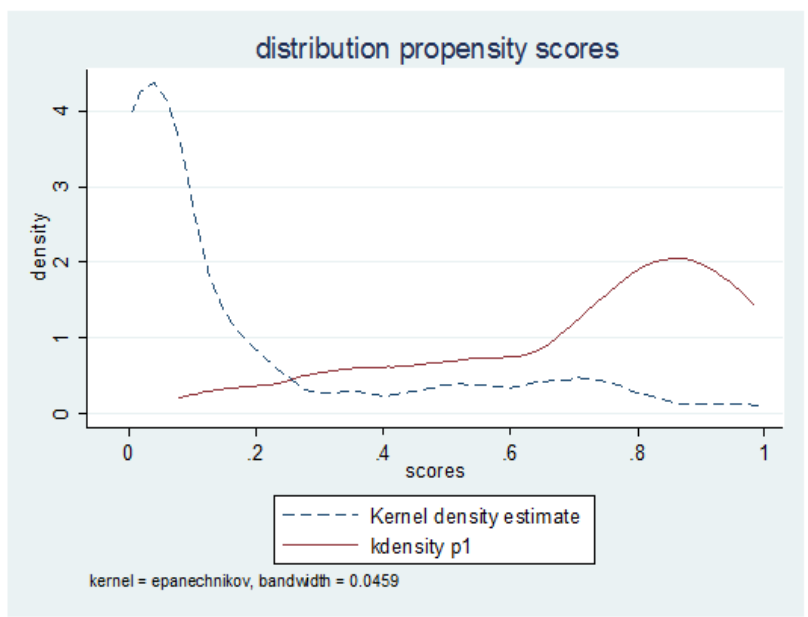

Figure 1. Common support graph

Source: Own computation based on PPT data (2019)

\section{Assessing the Matching Quality}

It is essential to note that two matching algorithms namely kernel matching (KM) and nearest neighbour matching (NNM 3:1), were used to examine the effects of PPT continued use on farmers' livelihood outcomes. However, these two different algorithms resulted in different quantitative findings, but with similar qualitative results. The matching algorithms resulted in a unique common 
support area and were based on somewhat different samples, thus resulting in the selection of various observations. Therefore, in assessing the matching quality, a balancing test was used to examine whether the differences in the explanatory variables or covariates in the matched sample category have been eliminated. Different propensity score quality indicators were used to check the quality of the matching process, before and after matching to determine the balance in the distribution of the covariates in all groups (Gwada, 2019). Results in Table 7, therefore, presents the mean differences, percent reduction in bias after completion of the matching algorithm, and a percent bias of the matched and unmatched group based on the observed characteristics used in the probit model of PPT continued adoption decision. After controlling for bias, a better balance was achieved in the matched sample for all the covariates. According to Rosenbaum and Rubin (1983), a percentage bias after matching of each covariate and the mean absolute bias should be less than $20 \%$ for validation of the balancing property. Overall, all variables satisfied this criterion after matching thus validated the balancing property. Therefore, PPT continuous users and nonadopters with similar observable characteristics were successfully matched. Therefore, 3:1 nearest neighbour and Kernel matching techniques were then considered as the best matching techniques for this study since they resulted in a significant reduction in bias after matching all the covariates.

Moreover, there were no significant differences in the mean distribution $(\mathrm{p}>t)$ in matched untreated and treated groups. Generally, there were insignificant p-values of the likelihood ratio test, greater reduction in total bias, and low pseudo $\mathrm{R}^{2}$ after matching for all algorithms as shown in Table 8. This implies that the propensity specification was successful with respect to the balancing of covariates distribution between the treated and untreated groups. Specifically, the mean standardized biases for all variables observed were 83.6 before matching. However, after matching, mean standardized biases significantly reduced to 12.60 and 17.6 for $3: 1$ nearest neighbour and kernel matching, respectively. This implies that $3: 1$ nearest neighbour matching produced the best matching quality in terms of low mean standardized biases. The pseudo- $R^{2}$ value before matching was 0.626 . By re-evaluating the scores based on matching the PPT continuous users' category and non-adopter category, and comparing the values of pseudo- $R^{2}$ before and after matching process, the finding revealed that the pseudo- $R^{2}$ values for the nearest neighbour matching (0.078) and the kernel matching (0.090) were significantly reduced to lower values after matching process. This implied that the matching process significantly reduced the selection bias thus the balancing property was satisfied. In other words, it implied that the regressors were randomly distributed in the treated group and untreated group. Further, p-values were all rejected after matching for all the matching algorithms implying that there was no difference in the distribution of the observed covariates between treated and control groups. The total percentage reduction bias for NNM and KM was $84.93 \%$ and $78.95 \%$, respectively. However, this was above the recommended value of $20 \%$ suggested by
Rosenbaum and Rubin (1983), thus indicating that the matching process significantly reduced the selection bias.

\section{Hidden Bias and Sensitivity Analysis}

It is vital to note that propensity score matching is designed to only control for the selection bias in the observable variables. This calls for the need to test or check for the hidden bias. This is based on the Average Treatment Effect on the Treated (ATT) sensitivity to hidden bias resulting from unobservable variables especially after matching. According to Rosenbaum and Rubin (1983) an unobserved variable may simultaneously influence individual assignment into the treatment group as well as the welfare outcomes. This might result in hidden bias thus leading to inaccurate and non-robust matching estimators. To solve this issue, a bounding approach or sensitivity analysis is used to evaluate how strongly unobserved factors might affect the treatment selection process to alter the matching analysis implications (Rosenbaum and Rubin, 1983).

This bounding approach involves the calculation of upper and lower bounds with a Wilcoxon sign-rank test to test the null hypothesis of no participation effect for different hypothesized values of unobserved selection bias (Rosenbaum and Rubin, 1983). The absence of a hidden bias means that the selection process indeed ensured that two parties having the same observed covariates have the same chances of getting the treatment, resulting in the odds ratio of one. Under the absence of hidden bias assumption, $Q \_m h+$ for overestimation of the treatment effect and $Q_{-} m h$ - for underestimation of the treatment effect resulted in a similar result or rather an odd ratio of one, implying the unobserved selection bias or absence of hidden as shown in Table 9.

\section{Effect of continual PPT uptake on Consumption Expenditure, Poverty Status, and Household Dietary Diversity}

After getting a common support condition and the best matching algorithms selected to match the different propensity scores of PPT continuous users (treated) to those of non-adopters, the average treatment effects on the treated (ATT) were estimated. The results of kernel matching (KM) and 3:1 nearest neighbour matching (NNM) showing the effect of PPT adoption and continued use on smallholder livelihood outcomes are presented in Table 10. The livelihood outcomes are measured by per capita household consumption expenditure per day, squared poverty gap, and household dietary diversity. Overall, using 50 times bootstrapping for testing of the statistical significance, the results of the two matching methods indicate that continual uptake of PPT had a positive significant effect on per capita household consumption expenditure per day and household dietary diversity score. For 3:1 nearest neighbour matching method, per capita household consumption expenditure per day and household dietary diversity scores were positively influenced by continual uptake of PPT and were both statistically significant at $1 \%$ level. 
RAAE / Gwada et al., 2021: 24 (1) 37-55, doi: 10.15414/raae.2021.24.01.37-55

Table 7: Mean differences in covariates before and after matching

\begin{tabular}{|c|c|c|c|c|c|c|c|c|}
\hline \multirow[b]{2}{*}{ Variable } & \multirow[b]{2}{*}{ Sample } & \multicolumn{2}{|l|}{ Mean Sample } & \multicolumn{2}{|l|}{ Bias } & \multirow{2}{*}{\multicolumn{2}{|c|}{$\begin{array}{l}\text { t-test } \\
\mathrm{t}\end{array}$}} & \multirow[b]{2}{*}{$p>t$} \\
\hline & & Treated & Control & Bias (\%) & Reduction bias (\%) & & & \\
\hline \multirow[t]{2}{*}{ Age of household head } & Unmatched & 54.865 & 49.93 & 50.3 & & & 3.42 & 0.001 \\
\hline & Matched & 52.257 & 52.435 & -1.8 & & 96.4 & -0.08 & 0.935 \\
\hline \multirow[t]{2}{*}{ Gender } & Unmatched & 0.824 & 0.539 & 64 & & & 4.17 & 0.000 \\
\hline & Matched & 0.714 & 0.831 & -26.2 & & 59 & -1.16 & 0.249 \\
\hline \multirow[t]{2}{*}{ Household head marital status } & Unmatched & 0.757 & 0.687 & 15.5 & & & 1.03 & 0.302 \\
\hline & Matched & 0.686 & 0.803 & -26 & & -67.3 & -1.11 & 0.269 \\
\hline \multirow[t]{2}{*}{ Education level of the household head } & Unmatched & 10.824 & 6.913 & 114.3 & & & 7.49 & 0.000 \\
\hline & Matched & 9.714 & 11.498 & -52.1 & & 54.4 & -2.07 & 0.142 \\
\hline \multirow[t]{2}{*}{ Natural logarithm of off-farm income } & Unmatched & 12.077 & 11.502 & 72.3 & & & 4.94 & 0.000 \\
\hline & Matched & 11.856 & 11.915 & -7.5 & & 89.7 & -0.34 & 0.736 \\
\hline \multirow[t]{2}{*}{ Household size } & Unmatched & 7.838 & 6.383 & 44.2 & & & 3 & 0.003 \\
\hline & Matched & 6.771 & 6.589 & 5.5 & & 87.5 & 0.27 & 0.790 \\
\hline \multirow[t]{2}{*}{ Tropical livestock unit } & Unmatched & 7.423 & 3.858 & 70.4 & & & 4.97 & 0.000 \\
\hline & Matched & 5.528 & 5.686 & -3.1 & & 95.6 & -0.15 & 0.881 \\
\hline \multirow[t]{2}{*}{ Total size of land owned } & Unmatched & 2.969 & 1.819 & 88.6 & & & 5.98 & 0.000 \\
\hline & Matched & 2.501 & 2.441 & 4.6 & & 94.9 & 0.21 & 0.833 \\
\hline \multirow[t]{2}{*}{ Land ownership } & Unmatched & 0.865 & 0.296 & 140.4 & & & 9.15 & 0.000 \\
\hline & Matched & 0.714 & 0.739 & -6 & & 95.7 & -0.23 & 0.821 \\
\hline \multirow[t]{2}{*}{ Perception of Striga weed severity } & Unmatched & 1.595 & 0.574 & 141.3 & & & 9.37 & 0.000 \\
\hline & Matched & 1.314 & 1.156 & 22 & & 84.5 & 0.78 & 0.437 \\
\hline \multirow[t]{2}{*}{ Perception of stem borer/ fall armyworm severity } & Unmatched & 1.622 & 0.617 & 140 & & & 9.28 & 0.000 \\
\hline & Matched & 1.371 & 1.028 & 47.8 & & 65.8 & 1.69 & 0.096 \\
\hline \multirow[t]{2}{*}{ Distance to the nearest administrative center } & Unmatched & 37.324 & 69.287 & -77.1 & & & -4.99 & 0.000 \\
\hline & Matched & 50 & 58.169 & -19.7 & & 74.4 & -0.87 & 0.385 \\
\hline \multirow[t]{2}{*}{ Number of farmer groups } & Unmatched & 3.919 & 2.252 & 69 & & & 4.66 & 0.000 \\
\hline & Matched & 2.943 & 3.088 & -6 & & 91.3 & -0.24 & 0.814 \\
\hline
\end{tabular}


Table 8: Propensity score quality indicators

\begin{tabular}{lrr}
\hline Matching algorithms & $\begin{array}{c}\text { Nearest neighbour } \\
\text { Matching NNM (3:1) }\end{array}$ & Kernel matching (KM) \\
\hline Before Matching & 0.626 & \\
Pseudo R ${ }^{2}$ before matching & 158.34 & 0.626 \\
LR chi ${ }^{2}$ before matching & 83.6 & 158.34 \\
Mean standardized bias before matching & 0.000 & 83.6 \\
Prob > chi & & 0.000 \\
After matching & 0.078 & \\
Pseudo R ${ }^{2}$ after matching & 7.61 & 0.090 \\
LR chi ${ }^{2}$ after matching & 12.6 & 8.70 \\
Mean standardized bias after matching & 0.868 & 17.6 \\
Prob > chi & & 0.795 \\
Total \% bias reduction & 84.93 & 78.95 \\
\hline
\end{tabular}

Table 9: Sensitivity analysis with Rosenbaum bounds

Gamma Q $\mathrm{mh}+\mathrm{Q} \_$mh- p_mh+ p_mh-

\begin{tabular}{lcccc}
\hline 1 & $\cdot$ & $\cdot$ & $\cdot$ & $\cdot$ \\
1.05 & $\cdot$ & -0.169 & $\cdot$ & 0.567 \\
1.1 & $\cdot$ & $\cdot$ & $\cdot$ & $\cdot$ \\
1.15 & $\cdot$ & -0.1691 & $\cdot$ & 0.567 \\
1.2 & -0.169 & $\cdot$ & 0.567 & $\cdot$ \\
1.25 & $\cdot$ & -0.169 & $\cdot$ & 0.567 \\
1.3 & -0.169 & -0.169 & 0.567 & 0.567 \\
1.35 & $\cdot$ & -0.169 & $\cdot$ & 0.567 \\
1.4 & -0.169 & -0.169 & 0.567 & 0.567 \\
1.45 & -0.169 & $\cdot$ & 0.567 & $\cdot$ \\
1.5 & -0.169 & -0.169 & 0.567 & 0.567 \\
1.55 & $\cdot$ & -0.169 & $\cdot$ & 0.567 \\
1.6 & -0.169 & -0.169 & 0.567 & 0.567 \\
1.65 & -0.169 & $\cdot$ & 0.567 & $\cdot$ \\
1.7 & -0.169 & -0.169 & 0.567 & 0.567 \\
1.75 & -0.169 & -0.169 & 0.567 & 0.567 \\
1.8 & -0.169 &. & 0.567 &. \\
1.85 & -0.169 & -0.169 & 0.567 & 0.567 \\
1.9 & -0.169 & -0.169 & 0.567 & 0.567 \\
1.95 & -0.169 & $\cdot$ & 0.567 &. \\
2 & -0.169 & -0.169 & 0.567 & 0.567
\end{tabular}

Note: Gamma: odds of differential assignment due to unobserved factors;

Q_mh+ : Mantel-Haenszel statistic (assumption: overestimation of treatment effect);

Q_mh- : Mantel-Haenszel statistic (assumption: underestimation of treatment effect)

p_mh+ : significance level (assumption: overestimation of treatment effect);

p_mh- : significance level (assumption: underestimation of treatment effect). 
Table 10 Effect of push-pull technology continued uptake on consumption expenditure, poverty status, and household dietary diversity

\begin{tabular}{|c|c|c|c|c|c|c|c|c|}
\hline \multirow[b]{2}{*}{ Matching Algorithm } & \multirow[b]{2}{*}{ Livelihood Outcome } & \multicolumn{2}{|c|}{ Sample size } & \multicolumn{3}{|c|}{ Mean outcome } & \multirow[b]{2}{*}{ Standard error } & \multirow[b]{2}{*}{ t-Statistics } \\
\hline & & Treated & Control & Treated & Control & ATT & & \\
\hline Nearest neighbour matching $(3: 1)$ & Per capita consumption expenditure per day (USD) & 35 & 115 & 2.04 & 1.45 & 0.59 & 25.778 & $2.29 * * *$ \\
\hline \multirow{5}{*}{ Kernel Matching } & Squared poverty gap & 35 & 115 & 0.028 & 0.097 & -0.069 & 0.037 & $-1.89 * *$ \\
\hline & Household dietary diversity & 35 & 115 & 10.114 & 7.352 & 2.762 & 0.672 & $4.11 * * *$ \\
\hline & Per capita consumption expenditure per day (USD) & 35 & 115 & 2.04 & 1.56 & 0.48 & 27.471 & $1.72 * *$ \\
\hline & Squared poverty gap & 35 & 115 & 0.028 & 0.077 & -0.049 & 0.036 & $-1.66 *$ \\
\hline & Household dietary diversity & 35 & 115 & 10.114 & 7.240 & 2.874 & 0.560 & $5.13 * * *$ \\
\hline
\end{tabular}

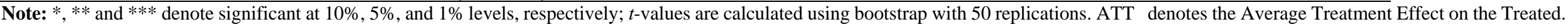


For the kernel matching method, per capita consumption expenditure per day and household dietary diversity score was positively influenced by continual uptake of PPT use and were statistically significant at $5 \%$ and $1 \%$ level, respectively as shown in Table 10 . The average treatment on the treated (ATT) column shows the difference in these livelihood outcomes between the treated (PPT continuous users) and control (non-adopters) groups (Gwada, 2019). On average, the treated group performed better than their counterparts as revealed by the positive difference. Overall, the results also indicated that the continual uptake of PPT has a significant negative effect on farmers' squared poverty gap. For 3:1 nearest neighbour matching method, the squared poverty gap was negatively influenced by continual uptake of PPT and was statistically significant at a 5\% level. For the kernel matching method, the squared poverty gap was negatively influenced by the continual uptake of PPT and was statistically significant at the $10 \%$ level. The effect of continual uptake of PPT on household per capita consumption expenditure ranges from KES 47.81/0.48 USD to KES. 59.02/ 0.59 USD daily. This implies that on average PPT continuous users were spending more on food and non-food items more than non-adopter of PPT.

The results imply that PPT technology has a positive impact on household consumption expenditure as it leads to significant improvements in soil fertility thus increasing cereal yields, milk, and dairy production (Gwada, 2019). More income raised from different enterprises under PPT is, therefore, used to purchase many food and non-food items. Chepchirchir et al. (2016) used the Tobit model and generalized propensity scores (GPS) to evaluate the effect of intensity of PPT uptake on household welfare in eastern Uganda and found that there exists a significant and positive impact of the intensity of PPT adoption on per capita consumption expenditure. Kassie $\boldsymbol{e t}$ al. (2014) and Lunduka et al. (2017) also revealed robust, significant, and positive effects of agricultural-related technologies uptake on per capita household consumption expenditure. Based on the nearest neighbour and kernel matching methods used, the estimated effect of continued use PPT on farmers' squared poverty gap is estimated to range from -0.069 to -0.049 . This implies that on average the severity of poverty among PPT continuous users is estimated to be $4.9 \%$ to $6.9 \%$ much lower than the corresponding value for PPT non-adopters (Gwada, 2019). This means that $P P T$ results in high productivity and more income that enable its adopter to spend above the poverty line thus reducing the depth of poverty. Nabasirye et al. (2012) also used the propensity score matching approach and found the same results where uptake of improved maize technology had a significant positive effect on productivity hence direct implications for the alleviation of poverty in Uganda. Kassie $\boldsymbol{e t} \boldsymbol{a l}$. (2014) also used general propensity score methodology and found that adoption and continued use of improved maize technology significantly declined the extent of poverty in rural Tanzania.

Finally, based on the nearest neighbour and kernel matching process used, the estimated effect of continual PPT uptake on farmers' household dietary diversity score ranges from 2.762 to 2.874 . In other words, PPT continuous users had access to approximately 3 food groups more than non-adopters. This also implies that PPT continuous users had better food access and a more diversified and quality diet thus higher nutritional outcomes compared to their counterparts. Ogot $\boldsymbol{e t}$ al. (2017) also reported that agricultural technologies positively impact maize productivity, income, and thus food expenditure resulting in a higher and better nutritional status. The direct effects of continual uptake of PPT on household dietary diversity score attributed to the productivity benefits PPT adopters enjoy over nonadopters, which usually come in the form of higher farm income leading to increases in consumption on various food items. The productivity changes result in improved livelihoods, thus resulting in better nutritional and economic well-being and poverty alleviation in many areas where it is being practiced.

\section{CONCLUSION}

Understanding the effect of continual uptake of PPT on livelihood outcomes is crucial for formulating sustainable small-scale agricultural policies. This study aimed to evaluate the effect of PPT continual uptake on livelihood outcomes of smallholder farmers in Homa Bay County, Kenya. Maize producers were classified into three groups namely PPT continuous users, PPT dis-adopters, and PPT non-adopters. The study concludes that significant variations in the socio-economic, farm and institutional characteristics exist across these PPT uptake groups. Probit regression results established that continual uptake of PPT was significantly influenced by age of household head, education level, total farm size owned, perception on Striga weed severity, land ownership, and perception on stem borer/ fall armyworm severity, all which had a positive effect. However, distance to the nearest administrative center negatively and significantly affected the continual PPT uptake. The study concludes that higher levels of education, aging, perception on stem borer, fall armyworm, and Striga weed as a major problem, larger land size, possession of land titles, and closeness to the nearest administrative center were significant in explaining the continual uptake of PPT among the surveyed households. Further, the study revealed that continual uptake of PPT had a positive and significant effect on per capita household consumption expenditure per day and household dietary diversity scores. However, it had a negative and significant effect on the depth of poverty as well as the severity of poverty among smallscale households. The study, therefore, concludes that continued uptake of PPT as integrated pest and weed management technology significantly impacts the livelihood outcomes of small-scale maize producers in Homa Bay county. Conclusively, continual uptake of PPT significantly improves consumption expenditure and access to a more diversified and nutritional diet, however, it reduces poverty. Also, the counterfactual results showed that the poverty gap between PPT continuous user and non-adopters could be closed if non-adopters were enabled to continuously practice the technology.

The study, therefore, recommends policies that will ensure intensive literacy development and extension 
training among young and elderly farmers as a strategy for promoting continual uptake of integrated pest and weed management technologies like PPT. The study also recommends land reforms to ensure the distribution and redistribution of land securities. In addition, there is a need for an integrated PPT development system that involves the collaboration of all stakeholders in ensuring continual supply, affordability, and accessibility of PPT components or inputs. Concerned stakeholders such as ICIPE should also continue supporting maize farmers with PPT inputs, as well as extension advice. Finally, in order to close the expenditure gap, nutritional gap, or the poverty gap between PPT-adopter and non-adopters, policymakers should consider policies that will improve efficiency or resource returns, and the number of resources of the nonadopters to the level of the PPT continuous users.

\section{Acknowledgments}

The authors would like to acknowledge the contributions made by the Faculty of Agriculture at Egerton University, and financial support from the African Economic Research Consortium (AERC). The advisory and technical supports from different enumerators, staff (ICIPE), and friends are also appreciated. We are also grateful to respondent farmers, and all others who provided positive criticism and input during this research.

\section{REFERENCES}

AWOTIDE, B., KARIMOV, A., \& DIAGNE, A. (2016). Agricultural technology adoption, commercialization, and smallholder rice farmers' welfare in rural Nigeria. Agricultural and Food Economics, 4(3): 1-24. https://doi.org/10.1186/s40100-016-0047-8

BECKER, O., \& ICHINO, A. (2002). Estimation of average treatment effect based on the propensity score. Stata Journal, 4:358-77. DOI: 10.22004/ag.econ.116022

CAIRNS, J., HELLIN J., SONDER. K., ARAUS, J., MACROBERT, F., THIERFELDER, C., \& PRASANNA, B. (2013). Adapting maize production to climate change in Sub-Saharan Africa. Food Security, 5: 345-360. https://doi.org/10.1007/s12571013-0256-X

CHEPCHIRCHIR, R., MACHARIA, I., MURAGE, A., MIDEGA, C., \& KHAN, Z. (2016). Impact assessment of push-pull technology on incomes, productivity, and poverty among smallholder households in eastern Uganda. A Paper presented at the 5th international conference of the African association of agricultural economists, held in Addis Ababa, Ethiopia, September 23-26,

2016. https://doi.org/10.0.85.244/ag.econ.246316

COOK, S., KHAN, Z., \& PICKETT, J. (2007). The use of 'push-pull' strategies in integrated pest management. Annual Review of Entomology, 52: 375-400. https://doi.org/10.1146/annurev.ento.52.110405.0914 $\underline{07}$

DEGROOTE, H., VANLAUWE, B., RUTTO, E., ODHIAMBO, G., KANAMPIU, F., \& KHAN, Z. (2010). Economic analysis of different options in integrated pest and soil fertility management in maize systems of western Kenya. Agricultural Economics, 41: $\quad 471-482 . \quad$ DOI: $\quad 10.1111 / \mathrm{j} .1574-$ 0862.2010.00459.x

DEHEJIA, R., \& WAHBA, S. (2002). Propensity score matching methods for non-experimental causal studies. The Review of Economics Statistics, 84(1), 151-161. https://doi.org/10.1162/003465302317331982

FOOD and AGRICULTURE ORGANIZATION, FAO, (2015). Production yearbook 2014. No. 85. Rome, Italy.

FOSTER, J., GREER, J., \& THORBECKE, E. (1984). A class of decomposable poverty measures. Journal of the Econometric Society, 2(1):761-766. https://doi.org/10.2307\%2F1913475

GOVERNMENT OF KENYA, GOK, (2012). Kenya Vision 2030. A Globally Competitive and Prosperous Kenya. Nairobi, Kenya: Government Printers.

GOVERNMENT OF KENYA, GOK (2018). Homa Bay County Government: Second County Integrated Development Plan 2018-2022.

GREENE, W. (2000). Econometric Analysis, $4^{\text {th }}$ Edition. Upper Saddle River, New Jersey: Prentice-Hall.

GWADA, R. O (2019). Effect of push-pull technology adoption and dis-adoption on livelihood outcomes of smallholder maize farmers in Homa Bay County, Kenya. Master's thesis, Egerton University, Nakuru, Kenya. Available at: http://irlibrary.egerton.ac.ke/jspui/handle/123456789/1926

HECKMAN, J., ICHIMURA, H., SMITH, J., \& TODD, P. (1998). Characterizing selection bias using experimental data. Econometrica, 66 (5): 1017-1098. https://doi.org/10.2307/2999630

INTERNATIONAL CENTRE OF INSECT PHYSIOLOGY AND ECOLOGY (ICIPE), (2018). Push-Pull IPM Technology. Available at: http://www.icipe.org/research/plant-health/push-pullipm-technology

KASSIE, M., JALETA, M., \& MATTEI, A. (2014). Evaluating the impact of improved maize varieties on food security in Rural Tanzania: Evidence from a continuous treatment approach. Food Security, 6(2): 217-230. 10.1007/s12571-014-0332-X

KENNEDY, G., BALLARD, T., \& DOP, M. (2011). Guidelines for Measuring Household and Individual Dietary Diversity. Food and Agriculture Organization of the United Nations. Rome, Italy. Available at: http://www.fao.org/3/a-i1983e.pdf 12.09.2019)

KENYA NATIONAL BUREAU OF STATISTICS, KNBS, (2009). Kenya Population and Housing Highlights. Nairobi, Kenya: Government of Kenya printing press.

KENYA NATIONAL BUREAU OF STATISTICS, KNBS, (2016). Statistical Abstract. Nairobi, Kenya: Government Printers. Available at: https://www.knbs.or.ke/download/statistical-abstract2016/ (Accessed 02.10.2019).

KENYA NATIONAL BUREAU OF STATISTICS, KNBS, (2017). Third Quarter 2017 Gross Domestic Product Report. Nairobi, Kenya: Government of Kenya printing Press. Available at: 
https://www.knbs.or.ke/?page $\mathrm{id}=3142$ (Accessed 02.11.2019).

KFIR, R., OVERHOLT, W., KHAN, Z., \& POLASZEK, A. (2002). Biology and management of economically important lepidopteran cereal stem borers in Africa. Annual Review of Entomology, 47: 701-731. DOI: 10.1146/annurev.ento.47.091201.145254

KHAN, Z., MIDEGA, C., AMUDAVI, M., HASSANALI, A., \& PICKETT, J. (2008a). On-farm evaluation of the Push-Pull technology for the control of stem borers and Striga weed on maize in western Kenya. Field Crops Research, 106(3): 224 -233. https://doi.org/10.1016/j.fcr.2007.12.002

KHAN, Z., MIDEGA, C., NJUGUNA, E., AMUDAVI, M., WANYAMA, M., \& PICKETT, J. (2008b). Economic performance of the push-pull technology for stem borer and Striga control in smallholder farming systems in western Kenya. Crop Protection, 27: 10841097. https://doi.org/10.1016/j.cropro.2008.01.005

KHAN, Z., MIDEGA, C., PITTCHAR, J., PICKETT, J., \& TOBY, B. (2011). Push-pull technology: A conservation agriculture approach for integrated management of insect pests, weeds, and soil health in Africa. International Journal of Agricultural Sustainability, https://doi.org/10.3763/ijas.2010.0558

KOTHARI, C. (2004). Research Methodology: Methods and Techniques, $2^{\text {nd }}$ Edition. New Delhi, India: New age international (p) limited.

KPADONOU, R., OWIYO, T., BARBIER, B., DENTON, F., RUTABINGWA, F., \& KIEMA, A. (2017). Advancing climate-smart-agriculture in developing drylands: Joint analysis of the adoption of multiple onfarm soils and water conservation technologies in West Africa Sahel. Land Use Policy, 61:196-207. https://doi.org/10.1016/j.landusepol.2016.10.050

LUNDUKA, R., MATEVA, K., MAGOROKOSHO, C., \& MANJERU, P. (2017). Impact of adoption of drought-tolerant maize varieties on total maize production in south Eastern Zimbabwe. Climate and Development, 2(4):567-598. https://doi.org/10.1080/17565529.2017.1372269

MARTIN, F. (2010). Impact assessment of push-pull technology developed and promoted by ICIPE and partners in eastern Africa. Nairobi, Kenya: International Centre of Insect Physiology and Ecology Science Press.

MIDEGA, C., PICKETT, J., ANTONY, H., PITTCHAR, J., \& KHAN, Z. (2016). Maize landraces are less affected by Striga hermonthica relative to hybrids in western Kenya. Weed Technology, 30(1):21-28. https://doi.org/10.1614/WT-D-15-00055.1

MURAGE, A., MIDEGA, C., PITTCHAR, J., PICKETT, J., \& KHAN, Z. (2015). Determinants of adoption of climate-smart push-pull technology for enhanced food security through integrated pest management in eastern Africa. Food Security, 7: 709-724. https://doi.org/10.1007/s12571-015-0454-9

MURAGE, A., OBARE, G., CHIANU, J., AMUDAVI, D, MIDEGA, C., PICKETT, J., \& KHAN, Z. (2012). The effectiveness of dissemination pathways on the adoption of push-pull technology in western Kenya.
Quarterly Journal of International Agriculture, 51(1): 51-71. https://doi.org/10.22004/ag.econ.155472

NABASIRYE, M., KIIZA, B., \& OMIAT, G., (2012). Evaluating the impact of the adoption of improved maize varieties on yield in Uganda: A propensity score matching approach. Journal of Agricultural Science and Technology, 2(3): 368- 378.

OBARE. G., MURAGE, A., CHIANU, J., AMUDAVI, D., PICKETT, J., \& KHAN, Z. (2011). Duration analysis of technology adoption effects of dissemination pathways: A case of push-pull technology for control of Striga weeds and stem borers in western Kenya. Crop Protection, 30(5):531-538. https://doi.org/10.1016/j.cropro.2010.11.009

OGOT, N., PITTCHAR, J., MIDEGA, C., \& KHAN, Z. (2017). Impact of push-pull technology on the nutritional status of farmers' children in western Kenya. African Journal of Food, Agriculture, Nutrition, and Development, 17(4): 12953-12974. https://doi.org/10.18697/ajfand.80.17050

ONYENEKE, R. (2017). Determinants of adoption of improved technologies in rice production in Imo State, Nigeria. African Journal of Agricultural Research, 12(11): 888-896. https://doi.org/10.5897/AJAR2016.11737

ONYENWEAKU, C., OKOYE, B., \& OKORIE, K. (2010). Determinants of fertilizer adoption by rice farmers in Bende Local Government Area of Abia State, Nigeria. Nigeria Agricultural Journal, 41(2): 16. https://mpra.ub.uni-muenchen.de/26116/

OSWALD, A. (2005). Striga control technologies and their dissemination. Crop Protection, 2: 333-342. DOI: $\underline{10.1016 / \text { j.cropro.2004.09.003 }}$

PICKETT, J., KHAN, Z., HASSANALI, A., HOOPER, A., \& MIDEGA, C. (2008). Desmodium species and associated biochemical traits for controlling Striga species: Present and future prospects. Weed Research, 48: 302-306. DOI: $10.1111 / \mathrm{j} .1365-$ 3180.2008.00641.x

RODENBURG, J., BASTIAANS, L., WELTZIEN, E., \& HESS, D. (2005). How can selection for Striga resistance and tolerance in sorghum be improved? Field Crops Research, 93: 34-50. https://doi.org/10.1016/j.fcr.2004.09.004

ROMNEY, D., THORNE, P., LUKUYU, B., \& THORNTON, P. (2003). Maize as food and feed in intensive smallholder systems: Management options for improved integration in mixed farming systems of east and southern Africa. Field Crops Research, 84(1):159-168. https://doi.org/10.1016/S03784290(03)00147-3

ROSENBAUM, P.R., \& RUBIN, D.B. (1983). The central role of the propensity score in observational studies for causal effects. Biometrika, 70(1): 41-55. https://doi.org/10.1093/biomet/70.1.41

SMITH, J., \& TODD, P. (2005). Does matching overcome LaLonde's critique of non-experimental estimators? Journal of Econometrics, 125(1-2): 305-353. https://doi.org/10.1016/j.jeconom.2004.04.011

VANLAUWE, B., KANAMPIU, F., ODHIAMBO, G., DEGROOTE, H., WADHAMS, L., \& KHAN, Z. (2008). Integrated management of Striga hermonthica, 
stem borers, and declining soil fertility in western Kenya. Field Crops Research, 107(2):102-115. https://doi.org/10.1016/j.fcr.2008.01.002

WOOLDRIDGE, J. (2005). Fixed Effects and Related Estimators for Correlated Random-Coefficient and Treatment Effect Panel Data Models. Review of Economics and Statistics, 87:385-390. https://doi.org/10.1162/0034653053970320

WORLD BANK (2008). World development report 2008: Agriculture for development, The World Bank, Washington, DC. Available at: $\underline{\text { http://documents.worldbank.org/curated/en/58725146 }}$ 8175472382/World-development-report-2008agriculture-for-development (accessed 15.11.2018)

YEYO, O. A., KIBOIJANA, L., WESONGA, R., \& NABUGOOMU, F. (2014). Logit Models for Household Food Insecurity Classification. American Journal of Theoretical and Applied Statistics, 3(2): 4959. https://doi.org/10.11648/j.ajtas.20140302.14. 